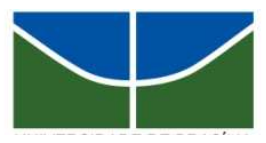

UNIVERSIDADE DE BRASÍLIA

Centro de Excelência em Turismo

Pós-graduação Lato Sensu

Curso de Especialização em Gastronomia e Segurança Alimentar

\title{
AVALIAÇÃO NUTRICIONAL DE REFEIÇÕES TERMOPROCESSADAS
}

Fernanda Lima Avena

Msc Verônica Cortez Ginani 


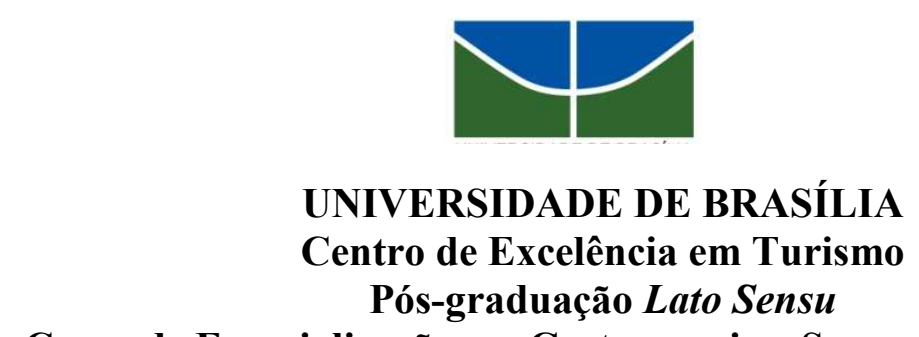

Curso de Especialização em Gastronomia e Segurança Alimentar

\section{AVALIAÇÃO NUTRICIONAL DE REFEIÇÕES TERMOPROCESSADAS}

Fernanda Lima Avena

Msc Verônica Cortez Ginani

Monografia apresentada ao Centro de Excelência em Turismo - CET, da Universidade de Brasília UnB, como requisito parcial à obtenção do grau de Especialista em Gastronomia e Segurança Alimentar 
Avena, Fernanda.

Avaliação Nutricional de Preparações Termoprocessadas /

Fernanda Avena. - Brasília, 2009.

xxvi, 26 f. : il.

Monografia (especialização) - Universidade de Brasília, Centro de Excelência em Turismo, 2009.

Orientador: Verônica Cortez Ginani.

1. Alimentação. 2. Alimentos. 3. Termoprocessados. 4. Nutrição. I. Avaliação Nutricional de Preparações Termoprocessadas. 


\title{
UNIVERSIDADE DE BRASÍLIA
}

Centro de Excelência em Turismo

Pós-graduação Lato Sensu

Curso de Especialização em Gastronomia e Segurança Alimentar

\section{Fernanda Lima Avena}

\section{Aprovado por:}

\author{
Professor orientador: Verônica Cortez Ginani
}

Professor: Raquel Braz Botelho

Professor: Karin Eleonora Sávio

Brasília, 31 de agosto de 2009. 


\section{DEDICATÓRIA}

Aos meus pais, pelo amor e apoio incondicional.

As minhas irmãs, que sempre estiveram do meu lado $e$ acreditaram em mim.

A Bruno, pelo apoio, incentivo e amor. 


\section{AGRADECIMENTOS}

A Prof. Msc. Verônica Cortez Ginani, na qualidade de orientadora, pelo apoio decisivo e dedicado na orientação da presente monografia;

A Prof. Dra Raquel Botelho, pela co-orientação e incentivo ao trabalho;

A todos os professores do Centro de Excelência em Turismo, pelos novos conhecimentos adquiridos;

Ao Departamento de Engenharia e Construção do Exército Brasileiro, que permitiu a realização da pesquisa em um de seus destacamentos;

E à Cellier, pela presteza no envio do material necessário à pesquisa. 


\section{EPÍGRAFE}

"A coisa mais bela que podemos experimentar é o mistério. Essa é a fonte de toda a arte e ciências verdadeiras."

(Albert Einstein) 


\section{RESUMO}

Introdução: Um dos desafios das Forças Armadas Brasileiras é a oferta de refeições aos seus combatentes, muitas vezes em locais inóspitos. Há, por conseguinte, a necessidade de fornecimento de alimentação com alta qualidade microbiológica, longo prazo de validade, facilidade de transporte, resistência a choques, facilidade de aquecimento e baixo custo. A refeição termoprocessada pode ser uma excelente opção para o fornecimento de refeições para tropas do exército, pois teoricamente o controle sanitário destes produtos é assegurado pelo próprio processo. No entanto, é necessário o desenvolvimento de novas pesquisas que avaliem os aspectos de qualidade nutricional, inerentes às exigências de saúde, para que conseqüências negativas não sejam acarretadas com a adoção do sistema.

Objetivo: Analisar a composição de refeições termoprocessadas, prontas ao consumo. Metodologia: Foi realizada em 4 etapas: a) seleção das preparações, que ao todo foram 16 preparações analisadas; b) cálculo da composição nutricional; c) comparação e análise dos resultados encontrados com as recomendações; d) recomendações de eventuais modificações para as preparações termoprocessadas.

Resultados: Foram encontrados altos valores de lipídios no arroz branco, feijão carioca com bacon, pratos principais que não continham vegetais, purê de batatas e salada de vegetais apresentando características que não eram esperadas nestas preparações. Quanto ao teor de sódio 9 das 16 preparações apresentaram valores maiores de $40 \%$ das recomendações para o almoço. Quanto à quantidade de fibra as preparações que apresentaram os maiores valores foram as que continham leguminosas.

Conclusão: Redução de condimentos industrializados, tais como caldos de vegetais e de carne; molho de soja, molho inglês e quantidade de sal de cozinha. Retirada aditivos como o glutamato monossódico e o monobissulfato de sódio. A refeição termoprocessada mesmo sendo prática, segura microbiologicamente, obteve valores de lipídios e sódio acima do recomendado e devem-se tomar providências para mudanças na formulação visando à adequação ao consumo humano e se tornando segura, também nutricionalmente.

Palavras-chave: termoprocessado, qualidade alimentar, embalagem flexível 


\begin{abstract}
Introduction: One of the challenges of Brazilian Military Forces is to offer meals to their combatants, often in inhospitable places. Therefore, there is a need for supplying food with microscopical high-quality, long-term validity, ease of transportation, shock resistance, facility of heating and low cost. The thermoprocessed meal may be an excelent option to provide meal for the army, because, in theory, the sanitary checking of those products is assured by their own process. Nevertheless, it is necessary new research to assess aspects of nutritional quality, which are inherent to health demands, that negative consequences are not entailed by adopting the system.

Aim: To analyze the nutritional composition of thermoprocessed meals, ready for consumption.

Methods: It was performed in 4 steps: a) selection of the preparations that were in all 16 preparations examined, b) calculate the nutritional composition c) compare and analyze results with the recommendations d) recommendations for possible changes to the preparations thermoprocessed.

Results: We found high amounts of lipids in white rice, bean with bacon, main dishes that contained vegetables, mashed potatoes and salad vegetables with characteristics that were not expected in these preparations. The sodium content of 9 of 16 preparations had values greater than $40 \%$ of recommendations for lunch. The amount of fiber preparations showed the highest values were those that contained legumes.

Conclusion: Reduction of industrial condiments, such as vegetable juices and meat, soy sauce, sauce English and amount of salt. Withdrawal additives such as monosodium glutamate and sodium monobissulfato. The thermoprocessed meal, even been practical and microbiologically safe, reached values of fat and sodium higher than recommended and arrangements should be made for changes in prescription in order to adapt human consumption and becoming nutritionally safer.
\end{abstract}

Keywords: thermoprocessed, food quality, flexible packaging. 


\section{LISTA DE TABELAS}

Tabela 1. Distribuição percentual de macronutrientes dos acompanhamentos

Tabela 2. Distribuição percentual de macronutrientes de pratos principais e pratos únicos ...13

Tabela 3. Distribuição percentual de macronutrientes das guarnições 15

Tabela 4. Quantidade de sódio por 100g da preparação de acompanhamentos. 16

Tabela 5. Quantidade de sódio por $100 \mathrm{~g}$ da preparação dos pratos principais e pratos únicos 17

Tabela 6. Quantidade de sódio por 100g da preparação das guarnições 18

Tabela 7. Quantidade de fibra por $100 \mathrm{~g}$ da preparação de acompanhamentos 20

Tabela 8. Quantidade de fibra por $100 \mathrm{~g}$ da preparação dos pratos principais e pratos únicos 20 Tabela 9. Quantidade de fibra por 100g da preparação de guarnições 


\section{LISTA DE ABREVIATURAS E SIGLAS}

FTP: Ficha técnica de preparação

NASA: National Aeronautics and Space Comunication

CAFA: Comissão de Alimentação das Forças Armadas

DabM: Diretoria de Abastecimento da Marinha

SBC: Sociedade Brasileira de Cardiologia

OMS: Organização Mundial de Saúde

ASBIA: Associação Brasileira de Alergia e Imunologia 


\section{SUMÁRIO}

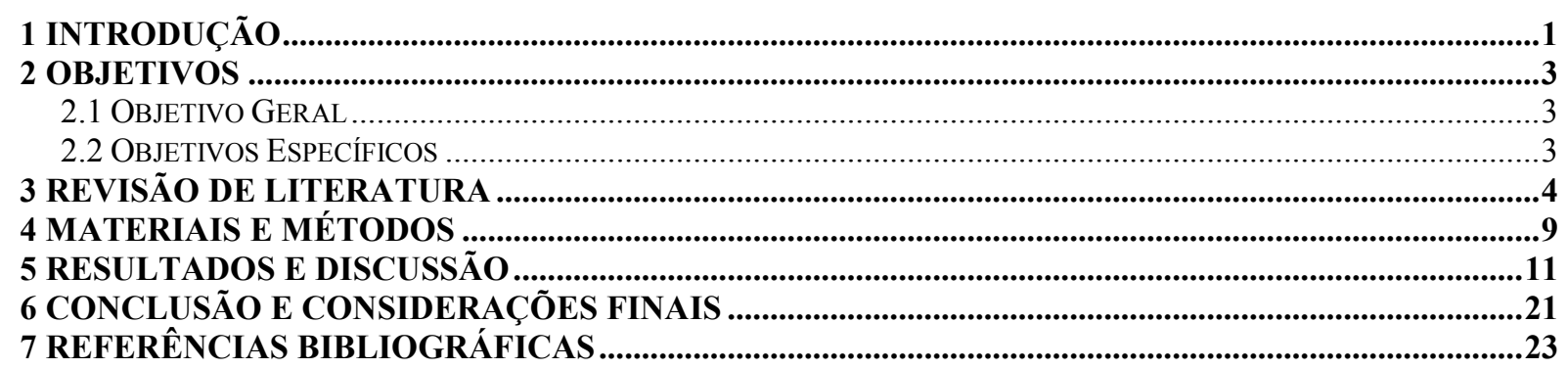




\section{INTRODUÇÃO}

É de grande importância uma alimentação adequada, do ponto de vista nutricional visando assegurar o crescimento e desenvolvimento, além do seu papel para a promoção e manutenção da saúde e bem-estar do indivíduo. Contudo, considera-se multifatorial os aspectos que resultam em uma alimentação saudável. A composição nutricional dos alimentos de acordo com as recomendações é relevante, mas fatores como diversidade cultural, preocupação com o ambiente, cultura local e atividades econômicas devem ser parte do processo, para que a alimentação saudável seja socialmente sustentável (BRASIL, 1999; BRASIL, 2006).

A produção de alimentos sofre variações conforme as preferências do consumidor, influenciadas por vários aspectos, tanto relacionados ao indivíduo quanto ao contexto social, cultural e econômico em que está inserido (KOTLER, 2000). Dessa forma o processo de urbanização e estilo de vida exigido nesse cenário, define um consumo alimentar específico, onde a praticidade e rapidez regem ações no setor. Grande parte dos trabalhadores tem dificuldades para realizar suas refeições em suas residências, utilizando os mais variados estabelecimentos prestadores deste tipo de serviço, que devem estar devidamente preparados com uma refeição de qualidade (KINASZ, 2006).

A qualidade em alimentos se refere a todos os processos que podem comprometer os padrões dos produtos, ou seja, na sua produção, na manipulação, os ingredientes usados, a embalagem, o tipo de armazenamento, o transporte e sua comercialização. De acordo com Proença (2005), a busca pela qualidade reflete além do valor nutricional as preocupações com os processos de produção e conservação dos alimentos.

A produção de refeições para coletividade deve merecer a atenção, como todo e qualquer processo produtivo, principalmente em relação ao controle de qualidade da gestão. A qualidade de uma refeição vai depender dos padrões e características, como peso, textura, 
sabor, cor, aroma, volume, da aceitação junto ao cliente e com os aspectos nutricionais que se pretende alcançar (PROENÇA, 2000).

As preparações desenvolvidas devem ser avaliadas para verificar seus constituintes e adequação quanto às recomendações de uma alimentação saudável. No entanto, somente a avaliação das características nutricionais e sensoriais de alimentos não garante que o alimento chegue às pessoas e possa ser consumido com segurança. Novas tecnologias que promovam não só o armazenamento e a facilidade do transporte, mas também a segurança do alimento é essencial (PROENÇA, 2000).

Nesse sentido, a preocupação com o bem-estar e a saúde tem levado a uma grande produção de estudos e pesquisas a respeito do tema.

Em face do exposto, o cenário mundial impõe aos profissionais da guerra novos parâmetros de planejamento. Assim, observa-se que as garantias de fornecimento continuado de apoio logístico aparecem como fundamentais para a manutenção de seus interesses e objetivos (BRASIL, 2009).

As Forças Armadas Brasileiras têm como desafio a oferta de refeições aos seus combatentes, muitas vezes em locais inóspitos. Há, por conseguinte, a necessidade de fornecimento de alimentação com alta qualidade microbiológica, longo prazo de validade, facilidade de transporte, resistência a choques, facilidade de aquecimento e baixo custo. (BRASIL, 2009).

As atividades desenvolvidas diariamente no exercício da função militar exigem tanto fisicamente quanto mentalmente do envolvido. O fato torna importante a alimentação, não só no que diz respeito à satisfação ao alimentar-se, mas também no que diz respeito às condições de elaboração dos alimentos produzidos dentro de padrões de segurança alimentar (SILVA, 2008). 
A justificativa da pesquisa está baseada em questões relacionadas com a alimentação fora do ambiente doméstico, sua qualidade na produção e especificamente com a alimentação destinada aos soldados do Exército Brasileiro. O conjunto citado revela a necessidade de se avaliar o atual sistema de alimentação empregado nas Forças Armadas (Exército Brasileiro), propondo de forma a obter um efetivo controle e garantia da qualidade e segurança dos alimentos do ponto de vista sanitário, o que não ocorre nas cozinhas militares (NERY et al, 2003), e principalmente nutricional.

Deste modo, retort pouch ou refeição termoprocessada pode ser uma boa opção para o fornecimento de refeições para tropas do exército que muitas vezes precisam realizar refeições em situações precárias, em que o preparo de alimentos pode ser uma dificuldade em função de indisponibilidade de equipamentos e insumos ou tempo para o preparo (BRASIL, 2009).

Teoricamente o controle sanitário destes produtos termoprocessados é assegurado pelo próprio processo. No entanto, é necessário o desenvolvimento de novas pesquisas que avaliem os aspectos de qualidade nutricional, inerentes às exigências de saúde, para que conseqüências negativas não sejam acarretadas com a adoção futura do sistema.

\section{OBJETIVOS}

\subsection{Objetivo Geral}

Analisar a composição nutricional de refeições termoprocessadas, prontas ao consumo.

\subsection{Objetivos Específicos}

- Avaliar as fichas técnicas de preparação FTP's dos produtos termoprocessados;

- Comparar a composição nutricional das preparações correspondentes (percentual de macronutrientes, quantidades de sódio e fibra). 
- Sugerir mudanças na formulação dos produtos termoprocessados para melhoria nutricional, caso se torne necessário.

\section{REVISÃO DE LITERATURA}

O crescimento do mercado de alimentação gerou a necessidade de desenvolvimento de pesquisas sobre alimentos, voltados à sua composição, aceitabilidade e consumo. E, de maneira geral, pesquisas neste campo, são iniciadas em desdobramentos militares, para posteriormente migrarem para o campo comercial, após os ajustes necessários (BRODY, 2004).

A composição nutricional dos alimentos ofertados deve atender a preceitos básicos correspondentes a uma alimentação saudável. Entende-se que práticas alimentares, com seus significados sociais e culturais, integram o conceito de alimentação saudável, uma vez que ocorrem por meio do consumo de alimentos e não de nutrientes. Os alimentos têm gosto, cor, forma, aroma e textura e todos estes componentes precisam ser considerados na abordagem nutricional. Os nutrientes são importantes, contudo, os alimentos não podem ser resumidos a veículos destes. O alimento como fonte de prazer também é uma abordagem necessária para promoção da saúde (BRASIL, 2005).

As profundas mudanças econômicas, sociais e demográficas ocorridas nas últimas décadas em decorrência da crescente modernização e urbanização provocaram alterações no estilo de vida da população e em particular nos hábitos alimentares. Tais modificações resultaram em alterações dos padrões de estado nutricional, ou seja, aumento da prevalência de sobrepeso e obesidade e diminuição da ocorrência de desnutrição, caracterizando assim a transição nutricional (FILHO, 2003; POPKIN, 2002)

$\mathrm{O}$ alto teor de açúcar, gorduras (principalmente de origem animal), alimentos refinados e a reduzida ingestão de alimentos fonte de carboidratos complexos e fibras, 
identificam-se como elementos comuns na dieta da população brasileira, independente do estado nutricional e da faixa de renda. Atualmente é comprovado que o predomínio desse tipo de padrão alimentar e o declínio da prática de atividade física estão associados com o aumento da obesidade e, conseqüentemente, com o aumento da prevalência de doenças crônicodegenerativas (MONTEIRO et al., 2000).

A Sociedade Brasileira de Cardiologia (SBC, 2007) recomenda a adoção dos preceitos divulgados pela AHA (American Heart Association) e adverte que a prevenção é a forma primária por meio da qual poderá ser observada a redução na mortalidade e na morbidade relacionadas com doenças do coração. A adoção de uma dieta com reduzido teor de lipídios, para diminuir as concentrações de lipídios séricos e ajustar o consumo de energia, e a atividade física são medidas preventivas. Justificam suas recomendações na baixa incidência de doença coronária em populações que habitualmente utilizam uma dieta com baixos índices de colesterol e gordura, ou uma dieta com baixo nível de colesterol e gordura saturada.

As doenças crônicas não-transmissíveis já são as principais causas de morte no mundo, às quais foram atribuídos 35 milhões de óbitos em 2005, quase $60 \%$ da mortalidade mundial e 45,9\% da carga global de doenças (MENDONÇA, 2004).

As recomendações internacionais de promoção da alimentação saudável evocam a importância da variedade de alimentos como fonte de nutrientes. O equilíbrio na escolha da ração alimentar está baseado nas necessidades individuais e a moderação pelo controle do consumo de alimentos energéticos, principalmente as gorduras devem ser consideradas no desenvolvimento de preparações destinadas a alimentação coletiva (FAO, 1996; OMS, 1990).

Os históricos das refeições prontas para o consumo evoluem nesse sentido. Essas preparações surgiram no mundo entre as décadas de 60 e de 70 , com a ida do homem à lua, onde os astronautas teriam que ficar confinados por grande período de tempo. O programa da NASA esteve à procura de novidades e modernidade, em cardápios de fácil emprego, como 
forma de estímulo ao consumo e com requisitos de salubridade comprovada para o não comprometimento das atividades da equipe de astronautas (BRODY, 2004). A comida fornecida deveria ser psicologicamente estável, devido ao espaço de confinamento e deveria lembrar o ambiente familiar em um espaço nem tanto familiar como os foguetes. Esse tipo de refeição mostrou-se eficiente, tendo papel fundamental em diversos conceitos atrelados ao desenvolvimento e fornecimento de alimentos em condições adversas (VOIT, 2005).

As Forças Armadas norte-americanas incentivaram o desenvolvimento deste tipo de embalagem devido a sua funcionalidade, uma vez que este novo conceito representava menor restrição aos movimentos do soldado, menor risco de ferimentos durante longas caminhadas pela maciez, facilidade e rapidez de abertura, menor volume e menor peso; se comparados as latas, que eram utilizadas anteriormente. Comprovando-se as vantagens no uso militar, passou-se a comercializar este tipo de embalagem (DAL BELLO, 2007).

Diferencialmente e simultaneamente, a Europa encarou o novo conceito como uma alternativa ao congelamento e ao uso de embalagens metálicas e de vidro no processo de conservação de alimentos, pois seus custos eram menores que estes últimos. Relatam-se tímidas tentativas de introdução do conceito na Itália em 1960, Dinamarca em 1966 e Japão em 1969 (ROJA, 2008). De forma oposta o mercado americano não observou grandes vantagens contra as alternativas existentes que justificassem um desenvolvimento agressivo do novo conceito no varejo enquanto que na Ásia e na Europa, o novo conceito encontrou melhor aceitação para se desenvolver e chegar ao atual estágio de maturidade. Na década de 70, tendo-se observado uma boa relação custo-benefício, o mercado americano apresentou novo interesse neste conceito de embalagem e a partir de então o seu uso foi difundido nos mais diversos tipos de alimentos e largamente utilizado neste mercado (DAL BELLO, 2007).

No Brasil, a tecnologia de refeições termoprocessadas também se iniciou nas Forças Armadas, com as rações operacionais de combate. As rações operacionais de combate são um 
conjunto de alimentos, complementos e acessórios destinados a alimentar o militar em situações de campanha, combate, abandono, sobrevivência e naufrágio, quando não há disponibilidade do emprego da cozinha tradicional ou de refeitório organizado, por certo tempo. Podem ser utilizados a critério da Força (Marinha, Aeronáutica ou Exército), alimentos e complementos como pastilhas, doces, bebidas não alcoólicas, vitaminas e sais minerais (WILLI, 2007).

Anteriormente às refeições termoprocessadas, a alimentação em situações especiais era constituída por enlatados. Suas principais desvantagens é que eram pesados, volumosos e pouco saborosos e tinha uma única vantagem, o baixo custo. Ao final dos anos 90, outros alimentos em embalagens adequadas e resistentes foram incorporados a elas, como por exemplo, os alimentos desidratados e os liofilizados em pó. Tinham como principais vantagens serem leves e pouco volumosas, porém apresentavam desvantagens como o alto custo, a dependência de água para a hidratação, além de existirem poucas empresas no país fornecendo este tipo de refeição (WILLI, 2007).

Ao final dos anos 80, a aquisição de rações pela Marinha Brasileira teve início com sua obtenção em empresas que as forneciam montadas nos cardápios estabelecidos e aprovados pela Comissão de Alimentação das Forças Armadas (CAFA). Em vista disso, começou-se a procurar alternativas para que se conseguisse um salto em tecnologia e qualidade, ficando a cargo da Diretoria de Abastecimento da Marinha (DabM), a busca pela melhor alternativa. Achou-se duas opções, vindas das maiores empresas fornecedoras de rações militares do mundo, dos Estados Unidos e da França. A Marinha encomendou das duas empresas e fez testes de aceitabilidade nos seus combatentes, tendo melhor aceitabilidade as rações vindas dos Estados Unidos. Assim, a DAbM decidiu pelo importação da ração americana, incrementando assim sua ração operacional e melhorando o acondicionamento dos alimentos básicos em embalagens flexíveis esterilizáveis de pronto consumo, pois além de 
atender a necessidade da tropa, resolvia o problema do prazo de validade, em face da vida útil mínima de dois anos desse tipo de embalagem, permitindo inclusive a criação de estoques estratégicos (WILLI, 2007).

A embalagem flexível esterilizável, ou retort pouch, é composta por uma bolsa formada por um laminado em multicamadas, que após o seu fechamento, permite que os alimentos nela contidos sofram tratamento térmico (esterilização), resultando em um produto de maior estabilidade a temperatura ambiente e seguro microbiologicamente. Compondo-se basicamente de três materiais: uma camada externa de filme de polietileno tereftalato, responsável pela resistência; folha de alumínio em uma segunda camada, formando uma barreira contra gases, vapores, aromas, radiação e luz; internamente, um filme de polipropileno para a termossoldagem a fim de evitar o contato do produto com o alumínio (ROJA, 2008).

Atualmente, esta tecnologia pode ser encontrada em diversos setores, demonstrando sua versatilidade. Além das Forças Armadas que já a utilizam como ração militar, sendo empregada em missões na Selva Amazônica, no mar e em localidades especiais que possuem custo elevado para manter a logística necessária para suprir a estrutura de um refeitório. Este produto é encontrado também em redes de lojas do tipo fast food como complemento ou acompanhamento de pratos principais e molhos, trazendo agilidade na hora de montar uma refeição, reduzindo os custos logísticos e de armazenagem, além de garantir a fidelidade das características organolépticas ao longo do período de validade. Produtos com esta tecnologia também se revelaram como uma excelente solução para a alimentação de quem gosta de esportes de aventura por possuir seu volume reduzido, ser resistente ao transporte e manuseio e fáceis de serem aquecidos.

Rojas (2008), major intendente da aeronáutica do Brasil, defendeu dissertação de mestrado com o objetivo de desenvolver um processo de modernização das rações 
operacionais da Aeronáutica. Seu trabalho consistia em desenvolver refeição de pronto consumo na embalagem em retort pouch, para uso em viagens dos seus militares e para uso terrestre, em substituição ao sistema atual utilizado pelas Forças Armadas, o tradicional. O que se procurou avaliar, no entanto, foi somente a embalagem e sua funcionalidade, que pelo estudo se comprovou isto, portanto são necessários trabalhos que comprovem o valor e a qualidade nutricional atrelada a este tipo de refeição.

\section{MATERIAIS E MÉTODOS}

Trata-se de pesquisa transversal, realizada em 4 etapas: a) seleção das preparações; b) cálculo da composição nutricional; c) comparação e análise dos resultados encontrados com as recomendações; d) recomendações de eventuais modificações para as preparações termoprocessadas.

Etapa 1: Seleção das preparações e composição nutricional

Primeiramente foi pedida a lista de preparações ofertadas pela empresa de termoprocessados. Esta lista foi encaminhada para um responsável no Exército para que fossem sinalizadas as preparações de preferência que poderiam ser servidas aos soldados. Das 24 preparações disponíveis na empresa, 16 foram escolhidas para serem futuramente consumidas pelos militares.

Foram selecionadas, desta maneira, 16 (dezesseis) preparações. Sendo elas:

— Acompanhamento: arroz branco, feijão preto com caldo, feijão carioca com bacon;

- Pratos Principais e/ ou pratos únicos: strogonoff de frango, frango com vegetais (batata e cenoura), carne em cubos com vegetais (batata e cenoura), carne seca com abóbora, feijoada, baião de três (arroz, feijão e carne), risoto 
de carne com vegetais (batata e cenoura), picadinho de carne ao molho e espaguete à bolonhesa;

— Guarnição: purê de batatas, couve, mandioca e salada de vegetais (batata e cenoura).

\section{Etapa 2: Cálculo da composição nutricional}

Foi solicitado à empresa o envio das 16 fichas técnicas de preparação para análise da composição nutricional das preparações.

Para a estimativa da composição nutricional (percentual de gordura, quantidade de sódio e fibras) foi utilizado o software Dietwin versão Rótulo de Alimentos 2008 (base de dados - TACO, 2006), por ser uma das principais fontes nacionais sobre composição de alimentos. A composição nutricional dos alimentos em macro e micronutrientes, que não constavam no banco de dados do programa Dietwin foram inseridas de acordo com o rótulo de produtos.

\section{Etapa 3: Comparação e análise dos resultados encontrados}

Para comparação dos resultados, foi utilizada como referência a quantidade de $100 \mathrm{~g}$ da preparação. Os dados dos macronutrientes e fibras foram comparados com as recomendações atuais (BRASIL, 2005). Os do percentual de sódio com a recomendação da Sociedade Brasileira de Cardiologia (SBC, 2007). Para tanto, utilizou-se como base para críticas os percentuais pretendidos para uma refeição ofertada (almoço) sendo de 35\% (MACHADO; SIMÕES, 2008).

Contudo, sabe-se que os resultados são preliminares e necessitam de dados quanto ao consumo dos indivíduos estudados para confirmação da adequação ou não da refeição consumida, uma vez que não se sabe quantos gramas de alimentos são ingeridos.

Etapa 4: Recomendações de eventuais modificações para as preparações termoprocessadas 
Ao serem detectados níveis de nutrientes superiores as recomendações (BRASIL, 2005; SBC,2007) foram sugeridas modificações para as receitas de acordo com critérios estabelecidos pela Técnica Dietética (GINANI, 2004 e ARAÚJO et al, 2007).

\section{RESULTADOS E DISCUSSÃO}

No Brasil, ultrapassando as diferenciações regionais, de classe social ou de origem étnica, há uma combinação alimentar que marca o cotidiano, constituindo-se na comida básica do brasileiro: o feijão com arroz. Mesmo quando é servido um "prato principal”, arroz e feijão costumam ser servidos como acompanhamentos, sendo, dessa forma, quase que obrigatórios em pelo menos uma das refeições do dia e, talvez a principal fonte de proteínas de grande parte da população brasileira. (MACIEL, 2004).

Sob o ponto de vista nutricional, as leguminosas são importantes fontes básicas de energia, proteína, além de alguns minerais e vitaminas. Já o arroz, possui características nutricionais em que a maior parte da sua constituição é de carboidratos complexos (ARAÚJO et al, 2007).

As quantidades de aminoácidos disponibilizadas pelo feijão não é completo, mas a combinação com o arroz é considerada complementativa, pois o aminoácido crítico no arroz, a lisinia é beneficiado pelo que é mais abundante no feijão, a metionina e vice-versa (ARAÚJO et al, 2007).

A gordura é ingrediente de diversas preparações, além de representar um percentual importante na composição química de diferentes alimentos. Simultaneamente, verifica-se que a utilização de óleos e gorduras na preparação de alimentos pode significar um acréscimo importante deste nutriente na composição química (GINANI, 2004).

Ingredientes normalmente relacionados com o incremento da porção lipídica de uma preparação são os de origem animal tal como ovos, laticínios e carnes. Também influenciam o 
teor lipídico, a quantidade de óleos vegetais utilizados, além dos métodos de preparo que podem exigir o uso da gordura. Todos esses aspectos da preparação de alimentos devem ser revistos, para que ocorram substituições que não comprometam a aceitação do produto final.

Apesar das moléculas de lipídios exercerem papel importante no desenvolvimento das características sensoriais dos produtos, verifica-se que a adoção desta prática contraria as recomendações da OMS (2003), que preconiza consumo diário de gordura inferior a 30\%.

De acordo com a tabela 1, verificou-se que alguns acompanhamentos não apresentavam características que não eram esperadas na preparação. Tais aspectos observados no arroz branco e no feijão carioca, que apresentaram característica lipídica aumentada (em negritos valores alterados). Este resultado é atribuído ao uso de ingredientes como óleo de cozinha em excesso (3\%), no caso do arroz e do feijão carioca, o uso do bacon. Desta forma, é recomendada a modificação das quantidades utilizadas destes ingredientes visando à melhor adequação para redução calórica destas preparações.

O feijão preto com caldo apresenta característica protéica, estando os percentuais de acordo com o esperado.

Tabela 1. Distribuição percentual de macronutrientes dos acompanhamentos.

\begin{tabular}{lccc} 
Preparação em 100g & \%CHO & \%PTN & \%LIP \\
\hline Arroz Branco & 68,61 & 7,29 & $\mathbf{2 4 , 1 0}$ \\
Feijão Preto com caldo & 55,81 & 31,68 & 12,51 \\
Feijão carioca com bacon & 52,14 & 18,33 & $\mathbf{2 9 , 5 2}$
\end{tabular}

De acordo com a tabela 2, verificou-se que algumas preparações não apresentam característica protéica e sim lipídica. Tal aspecto foi observado nos pratos que não continham em sua formulação, vegetais, tais como o strogonoff de frango, o picadinho de carne ao molho, o espaguete à bolonhesa e o baião de três. Excetuando-se a carne seca com abóbora 
que pela própria constituição da carne utilizada no preparo, possui o teor mais elevado de gordura.

Estas preparações necessitam de modificações quanto ao tempero, redução da quantidade de ingredientes calóricos ou a substituição por outros ingredientes.

Tabela 2. Distribuição percentual de macronutrientes dos pratos principais e pratos únicos.

$\begin{array}{lccc}\text { Preparação em 100g } & \text { \%CHO } & \text { \%PTN } & \text { \%LIP } \\ \text { Risoto de carne com vegetais } & 58,98 & 21,47 & 19,55 \\ \text { Carne seca com abóbora } & 14,12 & 46,07 & \mathbf{3 9 , 8 1} \\ \text { Feijoada } & 43,23 & 35,51 & 21,26 \\ \text { Baião de três } & 53,60 & 18,76 & \mathbf{2 7 , 6 4} \\ \text { Strogonoff de frango } & 17,30 & 44,40 & \mathbf{3 8 , 3 0} \\ \text { Frango com vegetais } & 35,75 & 50,92 & 13,33 \\ \text { Picadinho de carne ao molho } & 22,11 & 41,42 & \mathbf{3 6 , 4 7} \\ \text { Espaguete à bolonhesa } & 53,20 & 16,07 & \mathbf{3 0 , 7 2} \\ \text { Carne em cubos com vegetais } & 30,75 & 46,22 & 23,03\end{array}$

O strogonoff termoprocessado utiliza como ingredientes creme de leite e leite integral o que dilui o conteúdo do molho, porém, mesmo utilizando ingredientes em quantidades que irão diminuir o percentual de gordura, este ainda encontra-se elevado, pois a quantidade de molho (64\%) é alta para a quantidade de proteína (30\%) utilizada na preparação.

Na carne seca com abóbora a carne de charque, segundo a TACO (2006) contém mais gordura (16,8 g em $100 \mathrm{~g}$ de alimento), enquanto que o acém utilizado em outras preparações protéicas contém 6,1 g em 100 g, o que justifica seu alto teor lipídico.

O picadinho de carne ao molho apresentou percentual lipídico alto, pois em sua formulação contém caldo de carne industrializado e o próprio corte de carne, peito e quantidade utilizados (35\%), faz aumentar este percentual.

O espaguete à bolonhesa contém em sua formulação $3 \%$ de óleo de soja e $13 \%$ de carne moída que também ajuda a aumentar o percentual lipídico. 
O baião de três contém em sua formulação 3\% de óleo de soja e quantidade elevada de carne $(14,3 \%)$ em relação aos outros ingredientes que ajudam a compor este prato, como o arroz $(17,2 \%)$ e feijão $(18,5 \%)$, aumentando assim a quantidade de gordura existente na preparação.

As preparações que continham vegetais na sua formulação como o risoto, frango com vegetais e carne em cubos com vegetais apresentaram características protéicas, estando de acordo com o esperado. Os vegetais incluídos nestas preparações provavelmente ajudaram para redução lipídica. Porém, os vegetais utilizados não variaram, em todas as três preparações utilizou-se batata e cenoura, contribuindo assim para a monotonia do cardápio e não variabilidade de vegetais que devem ser consumidos pela população, de acordo com os preceitos instituídos no Guia Alimentar para a população Brasileira (Brasil, 2006).

A feijoada que é uma preparação que oferece quantidade relevante de lipídios à dieta, porém, a feijoada termoprocessada não apresentou percentual lipídico tão elevado, pois as carnes utilizadas foram somente carne seca, paio e o pernil que é um corte do suíno que apresenta menor quantidade lipídica na sua composição (11,1 g em $100 \mathrm{~g}$ do alimento cru) do que outras partes que são comumente utilizadas como a orelha $(19,9 \mathrm{~g}$ em $100 \mathrm{~g})$, costela $(19,8 \mathrm{~g}$ em $100 \mathrm{~g})$ e bacon $(60,3 \mathrm{~g}$ em $100 \mathrm{~g})$ (TACO, 2006).

Com relação às guarnições, há pouca variedade, as preparações são bem simples e excetuando-se a couve, as outras três preparações possuem como ingredientes principais vegetais com características glicídicas.

Como mostra a tabela 3, existe uma grande variação entre todos os itens analisados, verificando que duas guarnições apresentaram teor lipídico elevado, como o purê de batatas e a salada de vegetais, o que é justificado pelos ingredientes utilizados nas duas preparações e que elevaram estes valores.

Tabela 3. Distribuição percentual de macronutrientes das guarnições. 


$\begin{array}{lccc}\text { Preparação em 100g } & \text { \%CHO } & \text { \%PTN } & \text { \%LIP } \\ \text { Purê de batatas } & 16,27 & 4,09 & \mathbf{7 9 , 6 4} \\ \text { Couve } & 70,96 & 19,91 & 9,12 \\ \text { Mandioca } & 95,33 & 2,90 & 1,77 \\ \text { Salada de vegetais } & 49,03 & 6,13 & \mathbf{4 4 , 8 5}\end{array}$

No purê de batatas o teor de lipídio elevado explica-se pelo fato de que ingredientes aumentaram esses valores, como margarina e leite que juntas estão em quantidades maiores ( $9 \%$ e $15 \%$ respectivamente) que o ingrediente principal, a batata $(11 \%)$.

Já a salada de vegetais que não deveria se encontrar valores tão altos de lipídios, até pela própria constituição da preparação, porém, são acrescidos produtos que elevam estes valores como 3\% de óleo, 1,6\% de óleo composto e ainda caldo de "legumes" industrializado que contém percentual lipídico elevado, o que justifica esses valores altos.

Estas preparações também necessitam de modificações quanto ao tempero, redução da quantidade de ingredientes calóricos ou mesmo a retirada de ingredientes que elevem estes valores.

A couve e a mandioca apresentaram características esperadas para estas preparações, visto que a couve apresenta quantidade protéica alta (20,9 g em $100 \mathrm{~g}$ alimento cru) e a mandioca a característica de ser um alimento fonte de carboidratos (36,2 g em $100 \mathrm{~g}$ alimento cru) (TACO, 2006).

O sódio e o potássio são minerais essenciais para a regulação dos fluídos intra e extracelulares, atuando na manutenção da pressão sanguínea. O sal de cozinha, cloreto de sódio, é composto por $40 \%$ de sódio, sendo a principal fonte deste mineral na alimentação (BRASIL, 2005).

Apesar de não ter dados de consumo da população a qual a termoprocessada se destinará, tem-se uma noção pela quantidade calculada, se está elevada ou não, considerando- 
se o percentual (35\%) que a refeição representa para uma população saudável, com consumo de uma dieta de 2000 kcal (MACHADO; SIMÕES, 2008).

Outra referência é a recomendação de sódio, de acordo com a Sociedade Brasileira de Cardiologia (SBC, 2007), para uma pessoa ingerir, independente de sexo e idade é de até $6 \mathrm{~g}$ de sal por dia ou 2,4 g/dia de sódio. Ficando a quantidade para o almoço de $840 \mathrm{mg}$, os valores adicionados na tabela são para $100 \mathrm{~g}$ da preparação, podendo ficar super ou subestimados para a porção que será consumida pela população.

De acordo com a tabela 4, os acompanhamentos arroz e feijão preto apresentaram maior teor de sódio. Para estas preparações, a quantidade elevada de sódio encontrada está diretamente relacionada ao uso de sal em demasia (4\%) e no caso do feijão, há ainda o acréscimo de glutamato monossódico, substância que possui em sua formulação mais sódio que o próprio sal.

Tabela 4. Quantidade de sódio por $100 \mathrm{~g}$ da preparação de acompanhamentos.

$\begin{array}{lcc}\text { Preparação em } 100 \mathrm{~g} & \begin{array}{c}\text { Sódio }(\mathrm{mg}) / \\ 100 \mathrm{~g}\end{array} & \begin{array}{c}\text { \% em relação à quantidade de } \\ \text { sódio recomendada para o almoço } \\ (840 \mathrm{mg})\end{array} \\ \text { Arroz Branco } & 428 & \mathbf{5 1 \%} \\ \text { Feijão Preto } & 455 & \mathbf{5 4 \%} \\ \text { Feijão carioca com bacon } & 272 & 32 \%\end{array}$

O aditivo glutamato monossódico, é utilizado como realçador de sabor, porém é associado a alergias e eleva o teor de sódio da preparação e que não acrescenta valor nutricional algum e dado seu poder excitatório cerebral, pode gerar reações de irritabilidade e depressão (GUGLIARDI et al, 2002).

Considerando o consumo do arroz com o feijão já se tem, somente com esses dois produtos a quantidade recomendada de sal para o almoço, devendo-se tomar cuidado com o restante da alimentação ao longo do dia a fim de evitar que se ultrapassem as quantidades 
tabelares. E isso considerando que as porções serão estas, se forem superiores, somente com estes dois acompanhamentos já ultrapassa os valores recomendados.

Dessa forma, as modificações que poderiam ser realizadas para redução dos teores de sódio seria a diminuição do sal adicionado à preparação e a retirada do glutamato monossódico.

O feijão carioca com bacon não possui teores tão elevados de sódio quanto os outros acompanhamentos, pois o bacon já é um ingrediente salgado, pelo próprio processamento a que é submetido, a curagem e o sal é na porcentagem de menos de $1 \%$.

Com relação aos pratos principais e/ ou pratos únicos, na tabela 5 observa-se que $77 \%$ das preparações analisadas apresentaram elevados percentuais de sódio. Analisando de forma conjunta, nestas preparações, há a utilização de temperos como caldo de carne e "legumes" industrializados, molho de soja (shoyo), glutamato monossódico (que como já dito anteriormente contém quantidade mais elevada de sódio que o sal de cozinha e o próprio sal. Sendo que todos estes apresentam alto teor de sódio em sua composição e contribuem diretamente para o aumento deste nas preparações.

Tabela 5. Quantidade de sódio por 100g da preparação dos pratos principais e pratos únicos.

$\begin{array}{lcc}\text { Preparação em 100g } & \begin{array}{c}\text { Sódio }(\mathrm{mg}) / \\ 100 \mathrm{~g}\end{array} & \begin{array}{c}\text { \% em relação à quantidade de } \\ \text { sódio recomendada para o almoço } \\ (840 \mathrm{mg})\end{array} \\ \text { Risoto de carne com vegetais } & 417 & \mathbf{5 0 \%} \\ \text { Carne seca com abóbora } & 726 & \mathbf{8 6 \%} \\ \text { Feijoada } & 356 & \mathbf{4 2 \%} \\ \text { Baião de três } & 410 & \mathbf{4 9 \%} \\ \text { Strogonoff de frango } & 550 & \mathbf{6 5 \%} \\ \text { Frango com vegetais } & 293 & 35 \% \\ \text { Picadinho de carne ao molho } & 526 & \mathbf{6 3 \%}\end{array}$


Espaguete à bolonhesa

Carne em cubos com vegetais
$62 \%$

$36 \%$

A preparação que apresentou maior quantidade de sódio foi a carne seca com abóbora, provavelmente os valores elevados se devem ao uso da carne de charque, que mesmo dessalgada pode apresentar valores altos de sódio, uma vez que ainda não existam estudos que comprovem a diminuição destes valores. E, além disso, há o acréscimo de glutamato monossódico, o que aumenta mais o valor de sódio.

Quanto às guarnições, de acordo com a tabela 6, a mandioca é a que apresenta maiores valores de sódio em relação às outras guarnições. Para essas preparações, os valores de sódio também são atribuídos ao uso de caldo de "legumes" industrializado (couve e salada) e glutamato monossódico (salada e mandioca). Na receita do purê, foi encontrado outro aditivo, o metabissulfito de sódio. Entretanto seu consumo deve ser restrito, pois pode causar reações alérgicas, particularmente irritação de pele (ASBIA, 2007).

Tabela 6. Quantidade de sódio por $100 \mathrm{~g}$ da preparação das guarnições.

$\begin{array}{lcc}\text { Preparação em 100g } & \begin{array}{c}\text { Sódio }(\mathrm{mg}) / \\ 100 \mathrm{~g}\end{array} & \begin{array}{c}\% \text { em relação à quantidade de sódio } \\ \text { recomendada para o almoço } \\ (840 \mathrm{mg})\end{array} \\ \text { Purê de batatas } & 312 & 37 \% \\ \text { Couve } & 192 & 23 \% \\ \text { Mandioca } & 621 & \mathbf{7 4 \%} \\ \text { Salada de vegetais } & 175 & 21 \%\end{array}$

Dessa forma, a modificação que poderia ser realizada é a substituição do caldo de "legumes" industrializado por um feito artesanalmente que não leva sal na sua composição, tendo como atributo o de fornecer sabor e a retirada dos aditivos glutamato monossódico e metabissulfito de sódio, pelos mesmos motivos descritos anteriormente. 
O consumo adequado de sódio é uma das medidas preventivas para a hipertensão arterial, sendo importante manter ingestão dentro da recomendação. Segundo a Sociedade Brasileira de Cardiologia (2007), a hipertensão é um dos principais agravos à saúde no Brasil, podendo resultar em várias complicações, tais como doenças cérebro-vascular, doença arterial coronariana e vascular de extremidades, além de insuficiência cardíaca e da insuficiência renal crônica.

A fibra alimentar passou a ter sua importância reconhecida, e ser recomendada na alimentação, devido ao aumento da incidência de algumas doenças crônicas (obesidade, doenças cardiovasculares, diabetes, hipercolesterolemia, entre outras) que surgiram em populações dos centros urbanos de países industrializados, à medida que os alimentos naturais foram sendo substituídos pelos processados e refinados (PEREZ, 2007).

Uma ingestão adequada de fibras é fundamental para a manutenção normal do trato gastrointestinal e da saúde, sendo importante que esta faça parte da dieta da população sadia. Pesquisas realizadas nos últimos 25 anos mostram que os efeitos da fibra no trato gastrointestinal têm importantes conseqüências metabólicas que podem resultar em redução do risco de doenças crônicas degenerativas, tais como doenças cardiovasculares, certos tipos de câncer e diabetes mellitus tipo 2 (CUPPARI, 2002).

O termo fibra alimentar refere-se a partes dos alimentos vegetais que resistem à digestão. As principais fontes de fibra são os alimentos vegetais como grãos, tubérculos e raízes, as frutas, leguminosas e outros vegetais ricos em proteínas. A recomendação de consumo diário de fibras é de no mínimo $25 \mathrm{~g} /$ dia (BRASIL, 2005).

Com relação ao teor de fibras, a tabela 7 apresenta duas preparações que eram esperados altos teores de fibras, que as leguminosas contêm. O feijão possui componentes essenciais à dieta. As proteínas, os carboidratos, as vitaminas e os minerais, são os fatores nutricionais da maior importância. Além disso, possui conteúdo balanceado de fibra solúvel e 
insolúvel, o que é vantajoso para o consumo, em razão dos benefícios proporcionados pela ingestão da fibra (LONDERO, 2008).

Tabela 7. Quantidade de fibra por 100g da preparação de acompanhamentos.

$\left.\begin{array}{lcc}\text { Preparação em } 100 \mathrm{~g} & \text { Fibra/100g } & \begin{array}{c}\% \text { em relação à quantidade de } \\ \text { fibra recomendada para o almoço }\end{array} \\ & & (9 \mathrm{~g})\end{array}\right)$

Nos pratos principais, de acordo com a tabela 8, as preparações que apresentaram quantidades elevadas de fibra são as que possuem feijão na sua formulação. Mesmo possuindo vegetais na sua formulação estes não influenciam de forma significante no aumento do percentual de fibras.

Tabela 8. Quantidade de fibra por $100 \mathrm{~g}$ da preparação dos pratos principais e pratos únicos.

$\begin{array}{lcc}\text { Preparação em } 100 \mathrm{~g} & \text { Fibra/100g } & \begin{array}{c}\% \text { em relação à quantidade de fibra } \\ \text { recomendada para o almoço }\end{array} \\ & & (9 \mathrm{~g}) \\ \text { Risoto de carne com vegetais } & 0,86 & 9 \% \\ \text { Carne seca com abóbora } & 0,73 & 8 \% \\ \text { Feijoada } & 6,20 & \mathbf{6 9 \%} \\ \text { Baião de três } & 5,24 & \mathbf{5 8 \%} \\ \text { Strogonoff de frango } & 0,58 & 6 \% \\ \text { Frango com vegetais } & 0,87 & 10 \% \\ \text { Picadinho de carne ao molho } & 0,0 & 0 \% \\ \text { Espaguete à bolonhesa } & 0,77 & 8 \% \\ \text { Carne em cubos com vegetais } & 1,08 & 12 \%\end{array}$


A tabela 9 apresenta as guarnições e suas quantidades de fibras, em $100 \mathrm{~g}$ da preparação, mas mesmo em se tratando de vegetais, destes alimentos o que possui maior quantidade de fibras é a couve, e é também a que sofre menos adição de outros ingredientes no seu preparo, fato observado no purê de batatas que devido à proporcionalidade dos ingredientes da preparação a quantidade de fibras foi prejudicada.

Tabela 9. Quantidade de fibra por 100g da preparação de guarnições.

$\begin{array}{lcc}\text { Preparação em } 100 \mathrm{~g} & \text { Fibra/100g } & \begin{array}{c}\% \text { em relação à quantidade de fibra } \\ \text { recomendada para o almoço } \\ \text { Homens }(9 \mathrm{~g})\end{array} \\ \text { Purê de batatas } & 0,0 & 0 \% \\ \text { Couve } & 2,0 & 22 \% \\ \text { Mandioca } & 1,3 & 14 \% \\ \text { Salada de vegetais } & 1,4 & 15 \%\end{array}$

Porém as guarnições que existem termoprocessadas não deixam de ser uma opção visando aumentar o aporte de fibras ao longo do dia.

\section{CONCLUSÃO E CONSIDERAÇÕES FINAIS}

Com o desenvolvimento do presente trabalho, pode-se concluir que as refeições termoprocessadas não constituem uma preparação balanceada nutricionalmente, o que influencia diretamente na qualidade nutricional das mesmas. Para tanto, algumas recomendações, já sugeridas no decorrer do trabalho, serão aqui destacadas.

Recomenda-se que para a redução no teor de lipídios de uma preparação deve-se ocorrer ou pela substituição de matéria-prima ou de ingredientes (GINANI, 2004). Selecionar cortes de carnes magras, utilizar ingredientes modificados em seus teores de gordura são práticas importantes para elaborar preparações saudáveis e sensorialmente adequadas (ARAÚJO et al, 2007). 
Portanto, as mudanças necessárias para diminuir o percentual de gordura são com a substituição das carnes utilizadas para carnes mais magras, quantidades adicionadas de óleos, margarina, utilização de caldos de vegetais, frango e carnes feitos de forma artesanal, deixando de utilizar estes produtos industrializados que contêm elevado teor de gordura.

Visando a redução da quantidade de sódio das preparações, seria importante reduzir ou mesmo retirar a utilização de condimentos industrializados, tais como caldos de vegetais e de carne; molho de soja e molho inglês. A quantidade de sal de cozinha também está elevada em quase todas as preparações, deve-se diminuir.

Como discutido anteriormente algumas preparações termoprocessadas possuem aditivos que estão associados a alergias e processos psicológicos, que são de uso restrito ao ser humano como o glutamato monossódico e o monobissulfato de sódio, aditivos estes que não necessariamente precisam estar nas preparações se estas estiverem com ingredientes que naturalmente realcem seus sabores.

Na guarnição purê de batatas a sugestão é que se diminua as quantidades de leite e margarina para diminuição do percentual de lipídios e que se respeite a proporcionalidade dos ingredientes, já que este é um prato que o carboidrato deveria ser em quantidades mais elevadas que os outros macronutrientes.

A quantidade de preparações termoprocessadas disponíveis para consumo são pouco variadas e com isso o cardápio pode ficar repetitivo e enjoativo. Há a utilização dos mesmos vegetais em diversos pratos como a batata e a cenoura encontrados em pratos principais e em guarnições.

Há a necessidade de inclusão de novas preparações, principalmente regionais visto que são preparações do hábito alimentar da população, o que tornaria a refeição mais bem aceita.

Outro fator a se levar em consideração nos termoprocessados é a falta de preparações cruas, como hortaliças e frutas, que elevam a quantidade de fibra significativamente, devendo 
ser sempre incentivado por quem for montar o cardápio para os consumidores destas refeições.

Por fim, conclui-se que a refeição termoprocessada mesmo sendo prática, segura microbiologicamente, obteve valores de lipídios e sódio acima do recomendado. Fato preocupante devido a possibilidade da ocorrência de aparecimento de doenças crônicas não transmissíveis, adiantando ainda mais o processo de transição epidemiológica já existente no Brasil. Devem-se tomar providências para mudanças na formulação visando à adequação ao consumo humano e se tornando, portanto segura nutricionalmente e não só microbiologicamente.

\section{REFERÊNCIAS BIBLIOGRÁFICAS}

ARAUJO, WMC; MONTEBELLO, N. de P.; BOTELHO, R.A.; BORGO, L.A. Alquimia dos alimentos. Brasília: Senac, 2007.

ASBIA. ASSOCIAÇÃO BRASILEIRA DE ALERGIA E IMUNOPATOLOGIA. Alergia alimentar. Disponível em http://www.sbai.org.br/publico8.htm. Acesso em: 16 julho 2007. BRASIL. Ministério da Saúde. Coordenação Geral da Política de Alimentação e Nutrição. O que é uma alimentação saudável? Considerações sobre o conceito, princípios e características: uma abordagem ampliada. Maio, 2005. Disponível em http://nutricao.saude.gov.br/documentos, acesso em 17 de julho de 2009.

BRASIL. Ministério da Saúde. Política Nacional de Alimentação e Nutrição. Brasília, DF, 1999.

BRASIL. Ministério da Saúde. Guia Alimentar para a população Brasileira. Brasília, 2006.

BRASIL. Ministério do Desenvolvimento Social e Combate à Fome. Lei Orgânica de Segurança Alimentar e Nutricional - LOSAN. Brasília, D.O.U. - Diário Oficial da União; 
Poder Legislativo, de 15 de $\quad$ setembro de 2006.

BRASIL. Ministério do Exército. Disponível em $\underline{\text { http://www. }}$ exercito.gov.br/06OMs/gabcmtex/por657.htm, acesso em abril/2009.

BRODY, A.L. The Return of the Retourt Pouch, 2004. Disponível em http://books.google.

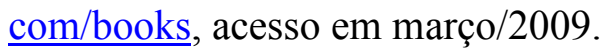

CUPPARI, L. Nutrição clínica no adulto. São Paulo: Manole, 2002.

DAL BELLO, M. D. Viabilidade técnico econômica da substituição de lata por "retort pouch.” Dissertação de mestrado, São Caetano do Sul, SP, 2007.

FILHO, M. B.; RISSIN, A. A transição nutricional no Brasil: tendências regionais e temporais.Cad. Saúde Pública, Rio de Janeiro, p. 180-191, 2003. (suplemento)

GINANI, V. Índice de aceitação de preparações regionais com teor lipídico modificado. 148p.

Dissertação (Mestrado em Nutrição Humana) Universidade de Brasília, Brasília, 2004.

GUGLIARDI, E.; BROCH, J. Falando aos trabalhadores rurais sobre alimentos, consumo crítico e solidariedade. Scripta Nova, Revista Electrónica de Geografía y Ciencias Sociales, Universidad de Barcelona, vol. VI, nº 119 (135), 2002.

KINASZ, T.R.; WERLE, H.J.S. Produção e composição física de resíduos sólidos em alguns serviços de alimentação e nutrição nos municípios de Cuiabá e Várzea Grande - Mato Grosso: questões ambientais. Revista Higiene Alimentar, volume 20, $\mathrm{n}^{\mathrm{o}}$ 144, p.64-71, setembro 2006.

KOTLER, P. Administração de marketing: a edição do novo milênio. São Paulo: PrenticeHall, 2000.

LONDERO, P. M. G.; RIBEIRO, N. D. ; CARGNELUTTI FILHO, A. Teores de fibra e rendimento de grãos em populações de feijão. Ciênc. agrotec. 2008, vol.32, n.1, pp. 167-173. 
MACHADO, F.M.S.; SIMÕES, A.N. Análise custo-efetividade e índice de qualidade da refeição aplicados à Estratégia Global da OMS. Rev. Saúde Pública, Feb. 2008, vol.42, no.1, p.64-72.

MACIEL, M. E. Uma cozinha à brasileira. Estudos Históricos, Rio de Janeiro, nº 33, 2004. OMS. A estratégia global sobre alimentação saudável, atividade física e saúde. Organização Pan-Americana da Saúde. Brasília, 2003. 60 p.

MENDONÇA, C.P.; ANJOS, L.A. Aspectos das práticas alimentares e da atividade física como determinantes do crescimento do sobrepeso/obesidade no Brasil. Caderno de Saúde Pública, Rio de Janeiro, v.20, n. 3, p.698-709, maio/jun, 2004.

MONTEIRO, C.A.; MONDINI, L.; COSTA, R. B. L. Mudanças na composição e adequação nutricional da dieta familiar nas áreas metropolitanas do Brasil (1988-1996), Revista de Saúde Pública, São Paulo, v. 34, n. 3, p. 251-258, jun. 2000.

NERY, C. R.; PEREIRA, M.B.; NASCIMENTO, M. V.; COELHO,S.C.; LOUZADA, S.R.; Nutrição e saúde no Exército Brasileiro. Revista de educação física. 2003 ,n.127, PP 34-40. OMS/FAO. Comunicado de imprensa conjunto da OMS/FAO 32. 23/04/2003. Relatório pericial sobre dieta alimentar, nutrição e prevenção de doenças crônicas. Roma, 23 de abril de 2003.

PEREZ, P. M. P. \& GERMANI, R. Elaboração de biscoitos tipo salgado, com alto teor de fibra alimentar, utilizando farinha de berinjela (Solanum melongena, L.). Ciênc. Tecnol. Aliment. 2007, vol.27, n.1, pp. 186-192.

PROENÇA, R.P.C. Inovação tecnológica na produção de alimentação coletiva. 2.ed. Florianópolis : Insular, 2000.

PROENÇA, R.P.C. Qualidade nutricional e sensorial na produção de refeições. Florianópolis: UFSC, 2005, 221 p. 
POPKIN, B. M. "An overview on the nutrition transition and its health implications: The Bellagio meeting." Public Health Nutrition 5(1A), p. 93-103, 2002.

ROJA, J. Avaliação de embalagens flexíveis esterilizáveis e alimentos prontos para o consumo para equipagens de embalagens de aeronaves e para consumo terrestre, Disssertação de mestrado, Campinas SP, 2008.

SBC. Sociedade Brasileira de Cardiologia. III Diretrizes Brasileiras sobre Dislipidemias e Diretriz de Prevenção da Aterosclerose Arquivos Brasileiros de Cardiologia. v, 77, supl.III, 2007.

SILVA, J.O. Ocorrência de aflatoxinas em arroz consumido por militares do exército brasileiro por cromatografia em camada delgada e cromatografia líquida de alta eficiência. Ciênc. Agrotec., Lavras. V. 32. n.4.p.1238-1244, jul./ago.,2008.

TACO - Tabela brasileira de composição de alimentos / NEPA-UNICAMP.- 2. ed. -Campinas, SP: NEPA-UNICAMP, 2006.

VOIT, D.C.; SANTOS, M.R.; SINGH, P. R. Development of a multipurpose fruit and vegetable processor for a manned mission to Mars. Journal of Food Engineering 77 (2006) $230-238$.

WILLI, Cmt. Rações alternativas de combate, uma experiência bem sucedida. São Paulo: V Seminário de alimentação das Forças Armadas, 2007. 44 slides, color. 